This is the post-print version of an article printed at www.springerlink.com. Jones, Glen A. (1991). Modest Modifications and Structural Stability: Higher Education in Ontario. Higher Education (Amsterdam), 21, 573-587.. For full footnotes and tables please see the final publication - available at

http://www.jstor.org/discover/10.2307/3447240?uid=2129\&uid=2\&uid=70\&uid=4\&sid=47699081868787

\title{
Modest Modifications and Structural Stability: Higher Education in Ontario
}

\section{Glen A. Jones}

\begin{abstract}
Policy change in Ontario higher education in the 1960s resulted in a series of structures designed to coordinate each of the two sectors in this binary system. Recent government initiatives may be characterized as attempts to initiate or stimulate change within the boundaries and constraints associated with a structure which has been relatively stable for twenty years. There has been some increase in regulation in the university sector through the establishment of targeted funding mechanisms, programme appraisal and approval mechanisms, and the government's legislated monopoly over degree-granting, but these changes have had little impact on the basic operations of the universities. Government initiatives in the community college sector have had some impact in terms of greater institutional differentiation, but little impact on institution stratification. The stability of the Ontario system can be attributed to the relative homogeneity of each of two clearly differentiated sectors, the limited role of the federal government in the policy arena, a structure which has deflected or rejected calls for structural change, and the failure of those who seek change to stimulate a public or political debate on higher education policy.
\end{abstract}

\section{Introduction}

There was a structural revolution in Ontario higher education in the 1960s. The province's universities struggled to expand in parallel with the tremendous increase in demand for their services. The provincial government dedicated immense resources to create and build new universities, and to support the increasing needs of those already in existence. An entire system of institutions designed to provide vocational and manpower training for a highly industrialized province was created and in full operation in only a few years, and the government developed a series of mechanisms and structures designed to coordinate the growth of each sector: the universities and the new colleges of applied arts and technology (CAATs).

The revolution was over by the early 1970s, when construction dust settled in an air of recession and government fiscal restraint, but the basic structures and relationships created during the 'revolution' continue to form the foundations of higher education in Ontario. Structures and mechanisms originally designed to support and co-ordinate growth were later employed to constrain or control system growth. Recent government initiatives, therefore, may be characterized as attempts to initiate or stimulate change within the boundaries and constraints associated with a relatively stable structure, to tinker with the rules rather than change the game.

The purpose of this article is to present an overview of recent policy change in Ontario higher education, with emphasis on the last decade, and to discuss the impact of these changes. I have limited the discussion to a review of policy change at what Clark (1983) refers to as the superstructure and enterprise levels of the system.1 Further research must be undertaken before any clear statement can be made as to the relationship between what I view as modest changes within the stable structures associated with the 
superstructure of Ontario higher education and activities at the understructure level. I will begin by describing the broad context, followed by separate discussions of the two major components of the provincial system, the universities and the CAATs, and those issues which involve both sectors. I will conclude by describing the various factors which have contributed to the relative stability of the Ontario system.

There are substantial differences in the way higher education is organized in each of the ten provinces, and one cannot suggest that Ontario, or any single province, represents a typical case. The relative diversity of institutional types in British Columbia sharply contrasts with the strict binary structures found in Manitoba and Ontario. There are also important differences in provincial policies for higher education, in the level of support provided to institutions (Tripartite Committee 1989), and in co-ordinating structures (Skolnik and Jones, in press). Unfortunately the scarcity of current research on higher education policy in Canada makes it difficult to obtain a national perspective on policy change.

\section{Background}

The Dominion of Canada was created by the British North America Act of 1867, a constitutional document which specified the structure and division of authority within the Canadian federal system. The provinces assumed, and continue to assume, the direct legislative and financial responsibility for education. In terms of post-secondary education, institutions operate under provincial charters, are coordinated by provincial bodies and legislation, and obtain the majority of their operating and capital support through direct provincial grants. The federal role is often described in terms of its responsibilities for the economy, employment, culture, and language, and perhaps as an over-riding theme, education for the development of a national consciousness and identity (Grant 1984). The federal government: provides the provinces with financial support for post-secondary education and health using a complicated mechanism of unconditional transfers called Established Programs Financing; funds three major granting councils which provide direct support for research and graduate scholarships; operates a variety of programmes which supports vocational and technical training, bilingualism and research; and provides financial assistance to students through a loans programme. While the provinces clearly play the primary role in the establishment of educational policy at all levels, the role of the federal government, as both a direct and indirect influence on these sectors, cannot be ignored, and there are many who argue that the federal role should be expanded to include the establishment of national policies and strategies for postsecondary education. The role of the federal government has been the subject of some debate, especially since recent budgets have decreased or frozen the growth of transfer payments to the provinces.

Post-secondary education in Ontario can be described as a binary structure of two sectors co-ordinated by a single government Ministry. Each sector is composed of institutions, a voluntary association representing the institutions, and an intermediary or 'buffer' body which provides advice to the Ministry of Colleges and Universities. Both sectors are 'public', in the sense that the public purse provides the institutions with the bulk of their operating revenues, but the two sectors are treated separately and differently by government, and, given their distinct identities and functions, are relatively insulated from each other. Basic information on the Ontario system is provided in Table

\section{The University Sector}

The structural foundation of the university sector was created in the 1960s, based on two complementary notions. The first is a relatively high level of institutional autonomy. Universities are corporations, each of which is controlled by an administrative board and an academic senate, except in the case of the University of Toronto which has a single Governing Council responsible for both administrative and academic matters. With representation from the provincial community, university administration, faculty, 
and students, these governing structures have authority over all internal matters including student admissions, programmes, hiring, and the allocation and expenditure of resources.

The second is the notion of equitable treatment of institutions by government. In order to avoid an annual carnival of institution budget requests, the government adopted a funding formula in 1967 so as to rationalize the allocation of operating support and to treat the institutions with some degree of equality. Subsequent policies have further adapted this notion, and all funding mechanisms include some allocative formula or competitive component, usually based on the recommendations of the intermediary body, which are designed to equalize and depoliticize the allocative process.

The university sector is composed of the 18 institutions which receive direct operating support through a common funding formula: 15 degree-granting universities, Ryerson Polytechnical Institute, the Ontario College of Art, and the Ontario Institute for Studies in Education. The Council of Ontario Universities, a voluntary association, represents university-sector interests to government and facilitates and promotes co-operative activities. The Ontario Council on University Affairs (OCUA), an intermediary body, provides the minister with advice on the university sector. The Council is composed of governmentappointed members, some of whom are drawn from the university community. The allocation of operating support to individual universities is determined through application of a funding formula. While the formula is enrolment-based, the mechanism includes moving-average calculations and a funding corridor for each institution, thus desensitizing the formula to immediate shifts in enrolment.

The allocation process been the subject of almost constant negotiation and revision, spawned by the universities' dissatisfaction with three formula-related issues. Firstly, there has been some discomfort with the specific calculations within the formula, and it has been regularly revised in response to concerns over programme weighting and negotiations over the institution-specific funding corridors. Second-ly, the formula mechanism provides for a deduction from the grant to a university which charges tuition fees in excess of an amount stipulated by government. Thus, the government effectively controls the level of tuition fees through the funding formula. A growing number of institutions are calling for a more marketdriven fee system, or, at the very least, greater flexibility in establishing tuition levels in order to address their financial needs. Finally, there is no relationship between the formula, which determines the share of the total grant to the sector which each institution receives, and the total level of government support available for allocation to the sector. There is a growing disparity between the level of support provided by government and the estimated needs of the system as identified by institutions. Even the more modest estimates of system financial requirements calculated by the intermediary body have not been accepted by government since 1977-78.

These issues have created a context in which institutional long-range planning is difficult since the level of overall support is determined annually, where institution-based initiatives and innovations are constrained by a funding mechanism which is relatively insensitive to change, and where government grants fail to adequately address the rising costs of maintaining the system. On the other hand, the mechanism reduces short-term variations in funding based on fluctuating enrolment patterns, reduces the incentive for institutions to seek funding through growth, and protects each institution from the impact of the actions taken by other institutions.

Given this context, the government has turned towards extra-formula funding mechanisms in order to target specific policy initiatives, though such grants account for a relatively small component of university operating revenues compared to formula allocations. While the universities do not like the idea of targeted funding, they nevertheless have responded positively to most of these initiatives and have sought greater financial flexibility through an increased emphasis on private fundraising and through recommending changes to provincial tuition policy, in opposition to the lobbying efforts of many student organizations. 
Targeted funding has become the major instrument for government-initiated policy change within the sector, and a number of mechanisms and funding 'envelopes' have been created to address special needs or changing demands. The two northern universities, for example, access the Northern Grants mechanism which provides support for the higher costs associated with serving the region and for special programmes required by the region. Institutions which operate degree programmes where French is the language of instruction have access to the Bilingualism Grants programme. Each of these programmes attempts to support the special needs of client groups, institutions, or regions using an allocative mechanism which is theoretically available to all sector institutions. More recent additions to the group of extra-formula grants have focused on two policy areas: accessibility, and research and technology.

The provincial government has had a long-standing policy that higher education should be accessible to all 'qualified' students. The policy was relatively easy to maintain during the period of the 1970s when the client population was stable or diminishing, but two recent demand-based changes have re-posed the question of how accessible the sector should be. Changes in the secondary school curriculum created a situation where students had the ability to complete their schooling in twelve rather than thirteen years, and demand studies suggested that this change would create a short-term increase in demand for higher education. Secondly, studies revealed a potential increase in participation rates, especially among females, from the secondary school population. The government, on the advice of OCUA, responded by creating an Accessibility Envelope designed to partially subsidize the incremental costs associated with increased enrolment. The programme provided an incentive for institutions to increase their undergraduate enrolment while respecting the notions of institutional autonomy and institutional equality, since institutions still controlled the definition of 'qualified student' through their admissions policies and the allocation employed an enrolment-growth based formula. While universities responded to the incentive programme by increasing undergraduate admissions, they were critical of the amount available for allocation, arguing that the allocation did not adequately cover the incremental costs associated with the policy goals.

A second policy area which has received considerable attention by government in the last decade is research and technology. The Research Overheads/Infrastructure Envelope is designed to address inadequacies in support for the indirect or overhead costs of existing research' (Ontario Council on University Affairs 1988: 212). A desire to maintain and increase the province's ability to compete in world markets, and a belief that long-term economic benefits may be obtained by encouraging linkages between knowledge creators (universities) and knowledge users (industry) have resulted in three types of extra-formula programmes, concentrating primarily on scientific research. The province has operated matching-grants programmes to support industry-sponsored, university-based research since 1981 . These programmes were designed to promote technology transfer through university-corporate linkages, but one preliminary analysis of the original programme suggests that there is at least some question about that programme's effectiveness in stimulating new corporate-sponsored research activity (Bell 1990). Secondly, the government operates a granting programme which provides partial support for collaborative research projects involving investigators from both university and industry. Finally, following a competitive process, the province approved and funded seven 'Centres of Excellence' in 1987. Each centre involves the linkage of expertise in one or more universities for the exploration of a specified research area involving ongoing contact with industry. Unlike the other targeted funding mechanisms described above, this programme has created new, often inter-university linkages through government funded, administratively autonomous, centres. These centres are distinct corporations with complex contractual relationships both with government and with relevant universities.

Two other policy areas must be considered in any discussion of change in the university sector. The first is the evolution of programme appraisal and approval mechanisms (see Watt 1987). In 1966 the universities established the Ontario Council on Graduate Studies to review all proposals for the 
establishment of new graduate programmes. The government quickly incorporated the review process into its funding mechanism: all new graduate programmes had to receive a positive review recommendation and the approval of government, based on the advice of OCUA, before programme enrolment could be calculated in the formula allocation. The review process has evolved to include the periodic appraisal of all graduate programmes, and a positive review is required for continued funding. The appraisal process functions as a form of self-regulation, though its structure and relationship to the funding mechanism have led some critics to suggest that the process represents an unnecessary constraint on innovation in graduate programming (Skolnik 1989).

Secondly, the 1983 Degree Granting Act provides the government with immense regulatory authority over the ability of institutions to grant degrees (Skolnik 1987). While this legislation has little direct impact on existing universities which have degree-grantinga uthorityu nder their charterl egislation, it requirest hat any out-of-province institution or any new private university, that is, a university which does not receive public funds, must seek and obtain government approval to offer degree programmes in Ontario. With one minor exception, the province has refused to provide this approval to indigenous private institutions. Out-of-province institu-tions which wish to establish satellite campuses in Ontario must provide evidence of programme quality and societal need. A small number of out-of-province, primarily American, universities have received permission to operate specific programmes, almost exclusively at the graduate level.

The programmes and mechanisms described above have resulted in only modest changes to the regulatory relationship between governments and universities and the classification of institutions in the sector. The basic structural elements of the sector, and the relationships that these structures create, have remained relatively unchanged for the last twenty years. There has been some increase in regulation through the establishment of targeted funding mechanisms, programme appraisal and approval mechanisms, and the government's legislated monopoly over degree-granting, but these changes have had little impact on the basic operations of the universities and their traditional roles and values.

Aside from Ryerson Polytechnic and the Ontario College of Art, which have different institutional missions than the universities and which have programmes which are weighted differently in the allocative formula, there is no institutional classification system in the university sector. Government policies have been designed to treat all sector institutions equally, and targeted funding has simply served to mildly reinforce the informal classification system of institutions that already exist: the 'northern' universities receive northern grants; the major 'research' universities receive the major benefits from programmes directed towards research and technology.

In summary, modest attempts at policy change have resulted in modest changes. The government has exhibited a consistent recognition, or at least toleration, of a relatively high level of institutional autonomy. While the government has received commission recommendations calling for greater sector rationalization and institutional differentiation (Commission on the Future Development of the Universities of Ontario 1984; Committee on the Future Role of the Universities in Ontario 1981), it has failed to even respond to these suggestions and has consistently pursued a policy of treating sector institutions as equals.

\section{The Colleges of Applied Arts and Technology}

In 1965 the Province of Ontario created an entirely new system of institutions: the colleges of applied arts and technology (CAATs). These institutions are designed to provide relevant vocational training in order to create a skilled workforce that can contribute to the economic expansion of a highly-industrialized province. The sector is both separate and distinct from the university sector, since the colleges do not have a formal transfer function and, except for a few institution-based arrangements, there is little 
articulation between the two sectors. The two sectors operate in parallel, with the premise that there is a certain 'parity of esteem' (see Dennison and Gallagher 1986).

As in the university sector, the structural foundation of the CAATs was created in the 1960s and early 1970s. Each college is a 'crown corporation', governed by provincial regulations and by a governing board composed primarily of members appointed by the intermediary body. Generally speaking, the twentythree colleges are multi-campus institutions located in, and serving the needs of, loosely defined geographic regions of Ontario. A voluntary association of sector institutions, the Association of Colleges of Applied Arts and Technology of Ontario, provides a forum for the discussion of policy and planning issues and for the representation of institution-based interests to government. The Council of Regents, an intermediary body comprised of government-appointed members, provides advice to the Ministry of Colleges and Universities and has authority for bargaining with the province-wide public sector unions which represent all college teachers and support staff. The provincial government reviews and approves college programmes and plans, provides operating grants and targeted funding mechanisms, and, in a general sense, co-ordinates sector activities.

Perhaps the largest changes in the sector involve the sources and mix of college revenues. The colleges receive funding from five basic sources: formula-based operating grants from the Ministry of Colleges and Universities; targeted programme support from the provincial Ministry of Skills Development; targeted programme support from the federal government; contract-based funding for industry-sponsored training; and tuition fees. With the possible exception of tuition, the relative importance of each of these funding sources has changed over the last twenty years, the most significant change being the reduction in the relative magnitude of funds from the federal government.

Operating grants are allocated through the use of a formula mechanism. The formula, while recognizing a variety of institutional factors emphasizes enrolment, and since it is responsive to enrolment growth, each institution's share of provincial grants is influenced by fluctuating enrolment patterns within the sector. The amount available for formula allocation is determined by government and, like the university sector, this amount has failed to increase at a rate that the institutions view as adequate. While these grants accounted for $60.6 \%$ of college revenues in $1979-80$, they accounted for only $56.7 \%$ in $1986-87$ (Vision 2000 1990a).

There have been considerable changes in the role of the federal government in the college sector. Federal programmes, which target specific training projects, have had a large impact on the programming decisions of many colleges. In order to reduce the impact and influence of changing federal policies, the province intervened, and many federal grants are now negotiated by, and routed through, the provincial Ministry of Skills Development. This Ministry accounted for 6.5\% of college operating revenues in 198687 , in contrast with $.9 \%$ in 1979-80. Direct federal programmes have declined in relative importance, from $18.6 \%$ (1979-80) to $13.8 \%$ (1986-87) of total revenues, though they continue to be a major influence on the college sector. < 
The colleges also enter into contractual relationships with industry where they obtain payment for the provision of specific services, usually short-term training programmes, though these types of arrangements accounted for less than $4 \%$ of total revenue in 1986-87. In that same year, tuition accounted for approximately $9.8 \%$ of revenues.

These changing patterns of support have had an obvious influence on the sector, especially since skills development, federal government, and industry-sponsored programmes are targeted towards specific training activities. Colleges are forced to respond quickly to changing government policies and priorities, and to the changing patterns of enrolment demand for post-secondary programmes, since the allocative formula is enrolment sensitive. The fact that the sector is viewed as both successful and relatively stable (Dennison and Gallagher 1986), points to the inherent plasticity of the institutional structures created in the 1960s, and to the effectiveness of the trilateral relationships involving government, the intermediary body, and the voluntary association.

There also has been a subtle shift towards greater institution specialization in response to government concerns over expensive duplication in specific programme areas. This shift has obviously led to greater institutional differentiation and heterogeneity, though the general mission and values of the sector, which emphasize teaching, have remained relatively constant. The newest college, in full operation as of the Fall of 1990, provides an excellent example of this shift. The college is differentiated from the others in that French is the primary language of instruction, though its central mission and values parallel the other institutions in the sector.

The issue of system-wide standards has been raised as part of a recent review of the college sector (Vision 2000 1990b). The task force has recommended that some 'system-wide body' develop standards for college programmes and undertake regular reviews of all programmes 'for the purposes of accreditation'. The task force did not specify the composition or mandate of the 'system-wide body', and the government has not yet responded to this recommendation.

One of the more troublesome issues in the sector is labour relations, especially during the last decade. Strikes by teaching staff in 1984 and 1989 disrupted sector operations, but the government has not initiated changes to the structure of these relationships, despite the recommendations of a recent commission (Gandz 1988). Labour difficulties have traditionally focused on workload and salary, both of which are negotiated on a provincial basis and present obvious constraints to institution-based decisionmaking.

Like the university sector, government initiatives have had a modest impact on the regulatory relationship between the institutions and government, but they have had little impact on the basic structures and relationships which were established in the 1960s. The CAATs have always had far less autonomy than the universities, and the institutions continue to be constrained by government regulation and targeted funding. Labour agreements, reached through province-wide bargaining, have introduced new constraints in the last decade.

Government initiatives, especially those relating to institution specialization and programme rationalization, have had some impact in terms of greater institutional differentiation, but little if any impact on institution stratification. There is no formal classification of institutions within the sector, and even the informal classification system, which groups the institutions into four geographic regions, has not been influenced by changes in government policy.

\section{Cross-sector Issues}

While the two sectors are distinct, in the sense that they have different missions and types of institutions, 
and relatively insulated from each other, there are a number of common issues which both sectors must confront. Neither sector, for example, has been able to convince government that larger increases in operating support are required if institutions are to continue to provide quality programmes and maintain a high level of accessibility. Despite the major lobbying efforts of individual institutions, the voluntary associations, and student and faculty associations, operating grants continue to be well below the levels recommended by sector representatives. Government, on the other hand, continues to argue that higher education is an important priority within public policy, but that public resources are strained by competing priorities, including the reduction of the provincial deficit. Institutions have responded to their financial difficulties in a variety of ways, including staff reductions, and reducing the number of courses which are available.

Both sectors have also been forced to address a variety of changing societal demands. Given the nature of the structural arrangements and the role of the provincial government, this response traditionally takes place at the level of the institution, especially in the university sector where there is a high level of institutional autonomy. Shifts in labour market and programme demand, for example, have forced institutions to consider shifting resources from low-demand to high-demand areas, with little or no government intervention. These short-term shifts, combined with an economy which is becoming more service-oriented, have had some impact on institutional planning. The colleges, for example, have been forced to contend with high-profile technology programmes that are receiving reducing numbers of qualified applicants. The institutional response to these pressures has varied considerably, as has their ability to respond given their programme mix and their ongoing, long-term commitments.

The institutions have also been forced to confront a variety of changing demands which are not directly related to higher education. Changes in federal and provincial taxation, including the movement towards a federal Goods and Services Tax, are of great concern to the institutions, especially since such changes may increase operating costs. Public pressure for a more heterogeneous workforce, supplemented by employment equity legislation, have forced institutions to review, and often change, their appointments policies. In the university sector, where women are under-represented among the professorial ranks in many disciplines, some institutions have established quotas or informal goals for hiring females and visible minorities. Human rights concerns have also brought the legality of mandatory retirement policies into question, and several cases, arguing that such policies are discriminatory under the Charter of Rights and Freedoms, will soon be heard by the Supreme Court of Canada.

Articulation between the two sectors has also become a topic of some discussion. The structural foundations of both sectors were created during a period when the prevailing view was that postsecondary education was a starting point for a life-long career. The two sectors were designed to provide different programmes and services to different client groups, and the issue of transferability was left in the hands of the institutions. The prevailing view of post-secondary education has changed, based on the notion of life-long learning and the reality of a workforce in which career change is common, but the structure of the Ontario system has not changed. There are currently only 27 transferability arrangements, most of which involve agreements between a single university and college concerning a single academic programme, and all other credit transfers are at the discretion of the individual universities (Marshall 1989). The issue is further confused by the fact that many colleges now offer post-degree programmes leading to an advanced diploma in such areas as applied research.

Both voluntary associations have now established committees on CAAT/- university relations. A review of the Ontario Council on University Affairs recommended that the Chair of each intermediary body be appointed to the other, though the government has not yet acted on this recommendation (Stubbs 1988).

Cross-sector articulation was one of the major issues addressed by Vision 2000, the first major review of the mission and operations of the CAAT sector. The task force, which included representatives of the 
major stakeholders of both sectors, recommended the creation of a 'provincial institute without walls for advanced training' which would 'facilitate the development and co-ordination of arrange-ments between colleges and universities for combined college-university studies' (Vision 2000 1990b). Like the U.K.'s Council for National Academic Awards, the institute would have the power to grant degrees based on some combination of college and university coursework. If accepted by government, such an initiative would represent a substantial change in higher education policy in the province, and have some impact on the operations of each sector.

\section{Analysis}

Ontario government policy concerning higher education has changed very little in the last twenty years. The basic structures and relationships created in the 1960s are still in place, and those changes which have occurred can be characterized as minor modifications within the boundaries and constraints associated with these stable structures. These modifications have had little effect on the regulatory relationship between government and institutions, and little if any impact on the informal classificatory relationship between institutions in each sector, or on the more formal classificatory relationship between the two basic types of institutions. The response to changing socio-political demands has been primarily at the institutional level, and while individual institutions have often changed internal policies and priorities to address these demands, such actions have had little impact on the basic structure and operation of the system.

There have been numerous calls for change in Ontario higher education. Problems associated with the lack of systemic articulation between sectors, especially the issue of credit transferability, have led some to argue in favour of greater province-wide, cross-sector co-ordination. A number of interested parties are lobbying to obtain degree-granting charters for proposed privately funded degree-granting institutions, perhaps suggesting that some important needs are not being met by the current institutions. Problems associated with the current level of government funding in the university sector have led to calls for greater sector-wide rationalization and institutional differentiation, either by limiting the role of some institutions or by increasing the role and authority of the intermediary body.

These problems, combined with targeted funding, the development of programme appraisal and approval mechanisms tied to funding, and the lack of articulation between sectors, would be the stuff of high political drama in many other jurisdictions. Why has there been so little change in Ontario higher education? Why has the system remained relatively stable?

Part of the answer lies in the relative homogeneity of each sector. While there are tremendous differences in size and programme offerings by institution, all of the CAATs share a common mission and mandate and all of the universities are comprehensive in that they are involved in teaching, at both the undergraduate and graduate levels, and research. The level of institutional homogeneity within each sector, reinforced by funding mechanisms designed to treat sector institutions as equals, reduces the pressure for 'upward academic drift' which has been a catalyst for change in other jurisdictions. This is not to suggest that all institutions agree with sector homogeneity, 5 but rather that it has been difficult for arguments of special status to win favour within the current arrangements. This is especially true in the university sector where there is little competition for funds, given the nature of the funding formula, or for students, since there is only limited competition with private or out-of-province universities and the funding arrangements reduce the incentive for institutions to seek funding through growth.

One might also suppose that there would be considerable pressure for 'upward drift' among colleges in an attempt to obtain university status, but this has not been the case. The two sectors are clearly differentiated. The notion of 'parity of esteem' between sectors has been generally accepted by both political and institutional decision-makers, and the general mission of the CAATs has been reaffirmed by 
a recent task force which included participants from major stakeholder groups (Vision $20001990 \mathrm{~b}$ ).

The limited role of the federal government in higher education policy has also contributed to system stability. There is no national policy for higher education, and federal-provincial disputes in this policy area have tended to focus on the level of unconditional transfers to the provinces. This 'soft federalism' in the higher education policy arena sharply contrasts with the 'hard federalism' of other federal systems, such as Australia, where federal government intervention has resulted in policy change (Smith 1990).

The balance and division of authority within the Ontario system have contributed also to system stability, in large part because there is little impetus for structural change. Structural change has been the subject of some discussion and debate, but there seems to be a consensus among system leaders that the current structural arrangements are appropriate. The universities are opposed to any change that would jeopardize their control of academic standards for degree programmes. The community colleges are opposed to any initiative that would effectively stratify the two sectors, placing the colleges in the role of supporting, and therefore serving, the universities. The provincial government is opposed to any change that would require additional public resources, limit accessibility, or reduce its regulatory role. There are also general concerns about changes that might destabilize, and as a result politicize, higher education in Ontario. Perhaps the greatest concern associated with structural change is the impact that any such initiative might have on institutional autonomy, especially in the university sector. The universities argue that most, if not all, of the problems associated with higher education in Ontario are a result of inadequate government grants, and they are strongly opposed to any government action that would reduce the current level of institutional autonomy. These structures, and the vested interests they imply, have deflected or rejected calls for structural change from those outside the system, or those who have little influence within the system.

Finally, system stability can be attributed also to the fact that those who seek change have been unable to raise their concerns to the level of public or political debate. Within the context of other social and political issues, such as health care, the environment, and poverty, the problems of higher education are seldom assigned a high priority, either by the media or by political leaders.

All of these factors have contributed to system stability, but a number of recent changes and events may have a dramatic impact on higher education policy in Ontario. The current constitutional impasse may result in important changes in federal-provincial relations and the division of authority between jurisdictions. The Canada-United States Free Trade Agreement, ratified in January 1989, may lead to some 'internationalization' of curriculum, especially in professional programmes since the Agreement allows for increased mobility of professionals between the two nations. The recommendations of the Vision 2000 review of the college sector may, if accepted by government, lead to greater cross-sector articulation, the creation of a new degree-granting institute 'without walls', and ongoing accreditation of college programmes based on common standards. While policy change in the last two decades can be characterized as modest modifications within a stable structure, these pressures and events may lead to important changes in Ontario government policy.

While the Ontario system represents an interesting case study of system stability during a period when many other systems have undergone dramatic change, the case also raises a number of important questions for further study. What is the relationship between structural stability at the level of the superstructure and the enterprise, to use Clark's terminology (1983), and activities at the understructure level? How does the situation in Ontario compare with other Canadian provinces, and if it is atypical, why? A national study of higher education policy in Canada aimed at addressing these and other basic questions would increase our understand-ing of policy change and its impact on higher education systems, as would comparative studies between Ontario and jurisdictions of comparable size and affluence which have undergone substantial structural change. 


\section{Acknowledgement}

The author would like to acknowledge the invaluable comments and suggestions provided by Professor Michael Skolnik.

\section{References}

Axelrod, P. (1982). Scholars andDollars: Politics, Economics, and the Universities of Ontario 1945-1980. Toronto: University of Toronto Press.

Bell, S. (1990). 'Using matchingg rants to facilitatec orporate-universityr esearchl inkages:a preliminary examination of outcomes from one initiative', Canadian Journal of Higher Education 20(1), 57-74.

Clark, B.R. (1983). The Higher Education System. Berkeley: University of California Press.

Commission on the Future Development of the Universities of Ontario (1984). Ontario Universities: Options and Futures. Toronto: The Commission.

Committee on the Future Role of the Universities in Ontario (1981). The Report. Toronto: The Committee.

Connell, G.E. (1987). University of Toronto Renewal - 1987. Toronto: University of Toronto Press. Council of Finance Officers,

Universities of Ontario (1989). A Decade of Financial Information: Ontario Universities 1978-79 to 198788. Toronto: Council of Ontario Universities.

Dennison, J.D. and Gallagher, P. (1986). Canada's Community Colleges, A Critical Analysis. Vancouver: University of British Columbia Press.

Gandz, J. (1988). The Report of the Colleges Collective Bargaining Commission. Toronto: Colleges Collective Bargaining Commission.

Grant, J.N. (1984). 'The educational role of the Federal Government', in Winchester, I. (ed.), The Independence of the University and the Funding of the State: Essays on Academic Freedom in Canada. Toronto: OISE Press, pp. 25-40.

Leslie, P.M. (1980). Canadian Universities 1980 and Beyond: Enrolment, Structural Change and Finance. Ottawa: Association of Universities and Colleges of Canada.

Marshall, R.A. (1989). 'College-university transfer arrangements existing in Ontario (questionnaire results)', in Colleges and the Educational Spectrum: Colleges and Universities (Vision 2000 Background Papers). Toronto: Ontario Council of Regents.

Ontario Council on University Affairs (1988). Fourteenth Annual Report 1987-88. Toronto: Ontario Council on University Affairs.

Skolnik, M.L. (1987). 'State control of degree granting: the establishment of a public monopoly in Canada', in Watson, C. (ed.), Governments and Higher Education - The Legitimacy of Intervention. Toronto: Higher Education Group, Ontario Institute for Studies in Education, pp. 56-83. 
Skolnik, M.L. (1989). 'How academic program review can foster intellectual conformity and stifle diversity of thought and method in the university', Journal of Higher Education 60(6), 619-643.

Skolnik, M.L. and Jones, G.A. (in press). 'Arrangements for coordination between university and college sectors in Canadian provinces', Canadian Journal of Higher Education.

Smith, R.H.T. (1990). 'Higher education in the public policy agenda: hard federalism and soft federalism'. Keynote address at the annual conference of the Canadian Society for the Study of Higher Education, Victoria, British Columbia. June 3.

Statistics Canada (1989). Education in Canada, A Statistical Review for 1987-88. Ottawa: Ministry of Supply and Services. Cat. 81-229. Stubbs,

J.O. (1988). The Report of the External Advisor to the Minister of Colleges and Universities on the Future Role and Function of the Ontario Council on University Affairs and Its Academic Advisory Committee. Peterborough, Ontario: External Advisor.

Tripartite Committee on Interprovincial Comparisons (1989). Interprovincial Comparisons of University Financing - Ninth Report of the Tripartite Committee on Interprovincial Comparisons. Toronto: Ontario Council on University Affairs.

Vision 2000 (1990a). 'The college system - an empirical snapshot', in Empirical Features of the College System (Vision 2000 Background Papers). Toronto: Ontario Council of Regents.

Vision 2000 (1990b). Vision2 000: Quality and Opportunity. Toronto: Ontario Ministry of Colleges and Universities.

Watt, L.A.K. (1987). 'Graduate studies in Ontario: the role of the universities and the role of government', in Watson, C. (ed.), Governments and Higher Education: The Legitimacy of Intervention. Toronto: Higher Education Group, Ontario Institute for Studies in Education, pp. 84-97. 